\title{
Crop Water Stress Index of an irrigated vineyard in the Central Valley of California
}

\author{
John H. Prueger ${ }^{1}$. Christopher K. Parry ${ }^{2}$. William P. Kustas ${ }^{3}$. Joseph G. Alfieri ${ }^{3} \cdot$ Maria M. Alsina $^{4} \cdot$ Héctor Nieto $^{5}$. \\ Tiffany G. Wilson ${ }^{3} \cdot$ Lawrence E. Hipps $^{6} \cdot$ Martha C. Anderson $^{3}$. Jerry L. Hatfield ${ }^{1} \cdot$ Fen Gao $^{3} \cdot$ Lynn G. McKee $^{3}$. \\ Andrew McElrone ${ }^{7} \cdot$ Nurit Agam $^{8} \cdot$ Sebastian A. Los $^{6}$
}

Received: 28 February 2018 / Accepted: 5 October 2018

(c) This is a U.S. government work and not under copyright protection in the U.S.; foreign copyright protection may apply 2018

\begin{abstract}
Water-limiting conditions in many California vineyards necessitate assessment of vine water stress to aid irrigation management strategies and decisions. This study was designed to evaluate the utility of a Crop Water Stress Index (CWSI) using multiple canopy temperature sensors and to study the diurnal signature in the stress index of an irrigated vineyard. A detailed instrumentation package comprised of eddy covariance instrumentation, ancillary surface energy balance components, soil water content sensors and a unique multi-canopy temperature sensor array were deployed in a production vineyard near Lodi, CA. The instrument package was designed to measure and monitor hourly growing season turbulent fluxes of heat and water vapor, radiation, air temperature, soil water content directly beneath a vine canopy, and vine canopy temperatures. April 30-May 02, June 10-12 and July 27-28, 2016 were selected for analysis as these periods represented key vine growth and production phases. Considerable variation in computed CWSI was observed between each of the hourly average individual canopy temperature sensors throughout the study; however, the diurnal trends remained similar: highest CWSI values in morning and lowest in the late afternoon. While meteorological conditions were favorable for plant stress to develop, soil water content near field capacity due to frequent irrigation allowed high evapotranspiration rates resulting in downward trending CWSI values during peak evaporative demand. While the CWSI is typically used to evaluate plant stress under the conditions of our study, the trend of the CWSI suggested a lowering of plant water stress as long as there was adequate soil water available to meet atmospheric demand.
\end{abstract}

Communicated by N.Agam.

John H. Prueger

john.prueger@ars.usda.gov

1 USDA ARS, National Laboratory for Agriculture and the Environment, Ames, IA 50011, USA

2 Dupont Pioneer, Johnston, IA 50131, USA

3 USDA ARS, Hydrology and Remote Sensing Laboratory, Beltsville, MD 20705-2350, USA

4 E \& J Gallo Winery, Viticulture, Chemistry and Enology, Modesto, CA 95354, USA

5 Institute for Food and Agricultural Research and Technology, Parc de Gardeny, Edifici Fruitcentre, 25003 Lleida, Spain

6 Plants, Soils and Climate Department, Utah State University, Logan, UT 84322-4820, USA

7 USDA Crops Pathology and Genetics Research, Davis, CA 95616, USA

8 Blaustein Institutes for Desert Research, Ben-Gurion University of the Negev, Sede-Boqer campus, Beersheba, Israel

\section{Introduction}

The United States is the fourth-largest wine-producing country in the world after France, Italy, and Spain. California produces 90 percent of all US wine. California vineyard production primarily takes place in five geographical regions of California. In 2015 total California grape production was estimated at over 371,150 ha $(918,000 \mathrm{ac})$ with an annual value of approximately $\$ 6$ billion. This production total represents table grapes 50,181 ha $(124,000 \mathrm{ac})$, dried grapes (raisins) $75,272 \mathrm{ha}(186,000 \mathrm{ac})$ and wine 246,049 ha (608,000 ac) (California Department of Food and Agriculture \& USDA National Agricultural Statistics Service 2015). The Central Valley of California dominates the geographical center of the state, extending lengthwise nearly $720 \mathrm{~km}$ $(\sim 450 \mathrm{mi})$ from the north-northwest to south-southeast and west to east approximately $60-100 \mathrm{~km}(\sim 40-60 \mathrm{mi})$, and accounts for over $70 \%$ of the wine grape production in California (California Department of Food and Agriculture 
\& USDA National Agricultural Statistics Service 2016). Other wine-producing regions include the North, Central and South Coast regions as well as southern California collectively making up the balance of the total wine production for the state of California.

In this study we focused on a vineyard in the Central Valley where the climate is characterized as hot-summer and warm-summer Mediterranean with little or no precipitation events occurring during the growing season requiring irrigation for wine grape production. The dominant method of irrigation is drip followed by furrow/flood. Drip irrigation uses substantially less water for vine production compared to furrow and flood irrigation. To sustainably continue irrigated vineyard production in this region, particularly during extended drought periods, improved tools for assessing vine canopy stress are needed. This has led others to develop crop water stress indices (CWSI's) using very high resolution aerial thermal imagery to define vine-only stress and water potential for irrigation scheduling (Bellvert et al. 2014). In this study we evaluate a CWSI derived from multiple infrared temperature sensors with variable view angles of a vineyard canopy near Lodi, CA.

\section{Plant water stress}

In an environment where hot temperatures, strong radiation, large vapor-pressure deficits (VPD's) and the potential for drought conditions dominate the growing season, plant water stress becomes an important crop management consideration as it has been associated with impacts to grape production related to variations in size, yield, and quality of the grapes. For example, Bramley and Lanyon (2002) found grape-quality variations in Australian vineyards to be driven by variations in soil water, which can be linked to variations in plant water stress. In California, many production vineyards induce vine water stress through deficit irrigation as a management practice to (1) maximize water-use efficiency of the vines and (2) enhance or improve quality of the wine grapes depending on varietal species and the intensity of the water stress (Bramley 2005). Cultural practices of modulating plant water stress have been found to affect fruit composition (Kennedy et al. 2002) while others reported on vine water stress effects on fruit growth and quality (Hardie and Considine 1976), fruit ripening (Matthews and Anderson 1987; Matthews et al. 1990) and total phenolic concentration which impacts wine sensory attributes (Matthews et al. 1987). Castellarin et al. (2007) found that plant water stress increased anthocyanin biosynthesis in the $V$. vinifera variety Merlot, which can increase the quality of the wine product. Ojeda et al. (2001) found that reduction in grape size and weight was exclusively caused by a decrease in pericarp volume and was independent of the intensity of water deficit or the stage of development. Their results support the hypothesis that early-season soil water deficits impact the cell wall elasticity, thus limiting the growth of pericarp cells.

One approach to assess plant water stress makes use of the difference between ambient air temperature $\left(T_{\mathrm{a}}\right)$ and vineyard canopy temperature $\left(T_{\mathrm{c}}\right)$. Canopy temperature was recognized as an indicator for crop water stress (Tanner 1963; Gates 1964). Additional studies showed an inverse correlation between leaf stomatal resistance and the rate of transpiration (Fuchs and Tanner 1966; Fuchs 1990; Jones 1992). In well-watered (low plant water stress) conditions, adequate transpiration cools the leaf surface, and in turn the bulk canopy, through the exchange of latent heat. This cooling causes $T_{\mathrm{c}}$ to be lower than $T_{\mathrm{a}}$ except during conditions of low VPD. High transpiration rates also require favorable meteorological conditions (sunny, warm temperatures, low humidity, moderate wind speeds and available soil water). The opposing case occurs when soil water availability and transpiration rates become low resulting in the leaf stomata restricting the size of their aperture, which reduces transpiration and its cooling effect causing leaf temperatures to be greater than the ambient air temperature (Gates 1964; Jones 1992). In the mid-to-late 1980s, infrared thermometer (IRT) canopy temperatures began to be used to assess plant water stress on the assumption that the difference between canopy and ambient air temperatures is an indicator of canopy stress conditions. Two consistent themes have been observed in the literature regarding plant water stress: (1) the lack of understanding of the complexities of induced water stress on vine, grape growth, and grape-quality enhancement; (2) a significant absence of the best appropriate method to measure and monitor plant water stress at the field (vineyard) scale. Knowing the current and historical plant water status at the field level is beneficial for growers in their irrigation scheduling and management practices. There are many methods available that attempt to provide a true indicator of crop water stress. Methods that directly determine plant physiological responses to water availability have the potential to be significantly more sensitive and accurate than indirect approaches like soil-moisture measurement.

Jones (2008) discussed the features that an ideal irrigation monitoring system would have. These features include: (a) sensitivity to small changes in the system, (b) rapid response measurement in "real time" to the surrounding conditions affecting plant water status and continual measurement, (c) readily adaptable to different crops, growth stages, environments, and environmental and meteorological conditions without the need of extensive recalibration, (d) robust and reliable, (e) easy to use with little training or knowledge of the measurement system, (f) automated to reduce labor requirements, and $(\mathrm{g})$ low setup and running costs. The CWSI is a method that can satisfy most if not all of the requirements specified by Jones (2008) where other methods fall short. 


\section{Crop Water Stress Index}

The Crop Water Stress Index (CWSI) was developed in response to a need to quantify plant water stress beyond the individual leaf. Empirical and theoretical concepts were developed by Idso et al. (1981) and Jackson et al. (1981), respectively. These first two developments were seminal in developing an operational and theoretical framework for monitoring plant water stress at the field scale which eventually led to advances for larger spatial-scale applications involving unmanned aerial vehicle- (UAV), aircraft- and satellite-based platforms. Other CWSI-related indices and methods that followed are described in detail in Maes and Steppe (2012). The CWSI is evaluated by normalizing the difference between canopy and ambient air temperatures with a lower no-stress boundary $\left(\partial T_{\min }\right)$ and an upper maximum water-stress boundary $\left(\partial T_{\max }\right)$. Physically the stress boundaries represent a relationship between a canopy temperature and the rate of transpiration of that canopy where the transpiration can be viewed as a significant component of evapotranspiration (ET). From an operational perspective the CWSI has been developed and applied to a considerable range of agricultural surfaces (e.g. Idso 1982; Feldhake et al. 1997; Möller et al. 2007; Testi et al. 2008; Berni et al. 2009; Erdem et al. 2010; Bellvert et al. 2014). To aid in improving water management strategies, CWSI indices have been used to detect the onset of water stress over various crop surfaces and incorporated into early detection decision support tools for initiating irrigation in response to a stress index (e.g. Irmak et al. 2000). This was an advancement to approaches that relied predominately on monitoring daily or weekly ET (Li et al. 2010) and soil-moisture content trends (e.g. Cárcova et al. 1998) to determine irrigation frequency and amounts. Others found that CWSI correlated well to yield in a variety of crops (e.g. Reginato, 1983; Nielsen 1990; Steele et al. 1994) and to $\mathrm{CO}_{2}$ fluxes (e.g. Li et al. 2010). These results suggest opportunities to use plant water stress monitoring to predict the impact on crop production and subsequent yields.

In a review by Jackson et al. (1988) the CWSI was expressed as:

CWSI $=\frac{\left(T_{\mathrm{c}}-T_{\mathrm{a}}\right)-\left(T_{\mathrm{c}}-T_{\mathrm{a}}\right)_{\mathrm{LL}}}{\left(T_{\mathrm{c}}-T_{\mathrm{a}}\right)_{\mathrm{UL}}-\left(T_{\mathrm{c}}-T_{\mathrm{a}}\right)_{\mathrm{LL}}}$

note that there appear to be four temperature differences in Eq. 1 but only the left numerator difference is an actual measured temperature difference $\left(T_{\mathrm{c}}-T_{\mathrm{a}}\right)$ between a targeted canopy temperature surface and ambient air temperature $\left(T_{\mathrm{c}}, T_{\mathrm{a}}\right)$ in ${ }^{\circ} \mathrm{C}$. The other three temperature differences, which are subscripted as LL (lower limit) and UL (upper limit), are computed limits (lower and upper) for $\left(T_{\mathrm{c}}-T_{\mathrm{a}}\right)$ and are used to normalize the measured $\left(T_{\mathrm{c}}-T_{\mathrm{a}}\right)$ difference. The upper and lower limits are computed as:

$\left(T_{\mathrm{c}}-T_{\mathrm{a}}\right)_{\mathrm{UL}}=\frac{r_{\mathrm{ae}} I_{\mathrm{cl}} R_{\mathrm{n}}}{\rho C_{\mathrm{p}}}$

$\left(T_{c}-T_{a}\right)_{L L}=\frac{r_{a e} I_{c l} R_{n}}{\rho C_{p}} *\left[\frac{\gamma}{\Delta+\gamma}-\frac{e_{s}-e_{a}}{\Delta+\gamma}\right]$

where $r_{\text {ae }}\left(\mathrm{s} \mathrm{m}^{-1}\right)$ is the effective aerodynamic resistance, $I_{\mathrm{cu}}$ and $I_{\mathrm{cl}}$ (dimensionless) are interception coefficients that are related to the partitioning of the net radiation $\left(R_{\mathrm{n}}\right.$ in W $\left.\mathrm{m}^{-2}\right)$ into turbulent latent and sensible heat fluxes $(\lambda E$ and $H$, both $\left.\mathrm{W} \mathrm{m}^{-2}\right), \rho$ is density of air $\left(\mathrm{kg} \mathrm{m}^{-3}\right), \mathrm{C}_{\mathrm{p}}$ is specific heat of moist air $\left(\mathrm{J} \mathrm{kg}^{-1} \mathrm{~K}^{-1}\right), \gamma$ is the psychrometric constant $\left(\mathrm{Pa}{ }^{\circ} \mathrm{K}^{-1}\right), \Delta$ is the slope of the saturation vapor-pressure curve $\left(\mathrm{Pa}^{\circ} \mathrm{K}^{-1}\right), e_{\mathrm{s}}$ and $e_{\mathrm{a}}$ are the saturation and actual vapor pressure $(\mathrm{Pa})$, respectively. It should be explicitly noted that the values for $I_{\mathrm{cu}}$ and $I_{\mathrm{cl}}$ (upper and lower boundary conditions) are 0.8 and 0.9, respectively (Jackson et al. 1988). An estimate of canopy net radiation was used for $R_{n}$ since this study focused solely on canopy temperature rather than a composite temperature of soil and canopy. The upper and lower boundary conditions represent temperature differences $\left(T_{\mathrm{c}}-T_{\mathrm{a}}\right)$ that would be obtained under well-watered conditions resulting in a minimum $T_{\mathrm{c}}-T_{\mathrm{a}}$ value or lower boundary, and under dry conditions resulting in no transpiration and thus maximum $T_{\mathrm{c}}-T_{\mathrm{a}}$ value or upper boundary condition. The difference between the upper and lower boundary conditions are related to $R_{\mathrm{n}}$ of the canopy where it has been assumed that for a dry or desiccated vegetation condition the reflected and emitted radiation would be greater than for a well-watered "green" surface. Furthermore, we introduced directly into Eqs. 2 and 3 the effective aerodynamic resistance $\left(r_{\mathrm{ae}}\right)$. This resistance term is a non-linear function of temperature and needs to be solved iteratively for both stable and unstable conditions. For this study, $r_{\mathrm{ae}}$ was calculated according to Kustas et al. (2016) where the Monin-Obukhov length is used to correct for atmospheric stability. The measurement of $T_{\mathrm{c}}$ combined with eddy covariance-measured ET (latent heat fluxes, $\lambda E$ ) offers the potential to apply the theoretically derived CWSI of Jackson et al. (1981). This approach makes use of the turbulent fluxes of water vapor and sensible heat $(\lambda E, H)$ and momentum measured with eddy covariance allowing for more accurate calculations of the aerodynamic and canopy resistance terms. However, this approach has not been widely used in vineyards to evaluate periodic, weekly and seasonal CWSI trends for use in irrigation scheduling. The objectives of this study is to (1) make use of the full suite of micro-meteorological measurements to evaluate the CWSI in a typical production vineyard in California and (2) bring attention to the unique diurnal 
trends of CWSI observed in this study. The diurnal trends observed in this study have the potential to change how often CWSI is observed throughout the day and the entire season when used for crop irrigation management. Instead of calculating CWSI mid-day as is the common practice, it may need to be observed for the entire day to determine the true level of stress of the crop being monitored.

\section{Materials and methods}

\section{Site description}

This study is part of the USDA-ARS Grape Remote sensing Atmospheric Profile and Evapotranspiration eXperiment (GRAPEX) conducted on two adjacent vineyards planted with the $V$. vinifera variety Pinot Noir. These vineyards are situated in the northern part of the Central Valley with coordinates of $38.29 \mathrm{~N} 121.12 \mathrm{~W}$ and are part of a large privately owned production vineyard. The two Pinot Noir vineyards are located near the southern and northern borders of the Sacramento and San Joaquin counties, respectively, where the Dry Creek forms a natural boundary between the two counties (Fig. 1). At this location the soil type is classified as a Kimball silt loam with a 0-2 percent slope. These soils were formed in an alluvium derived from mixed rock sources, predominately granite. Soils of the Kimball series are fine, mixed, thermic, mollic, Palexeralfs with slow permeability and moderate available water holding capacity with a potential of water becoming perched above a clay pan layer found about $100 \mathrm{~cm}$ below the surface (USDA Soil Conservation Service 1993b).

Climatologically this region is characterized by warm, dry conditions with an evaporative transpiration total ranging from 889 to $1270 \mathrm{~mm}$ of water during the growing season (Williams 2001; Semmens et al. 2016) which usually begins in early April and continues through the end of August. Typical air temperature averages can approach $22{ }^{\circ} \mathrm{C}$ and range diurnally from 16 to $38^{\circ} \mathrm{C}$ during the summer months. Total precipitation averages are about $24 \mathrm{~mm}$ during the growing season. Mean wind directions during the growing season at the site location tend to have a westerly component with mild wind speeds. The study site has two fields, a larger northern field (Site 1, 35 ha, 86 ac) and a second smaller field (Site 2, 21 ha, 52 ac) located approximately $400 \mathrm{~m}$ due south from Site 1 (Fig. 1). Site 1 is the more mature field planted in 2009 compared to Site 2 which was planted in 2011. Vine height for both fields averages approximately $2 \mathrm{~m}$, vine spacing within row (vine to vine) is $1.52 \mathrm{~m}$ and row spacing is $3.35 \mathrm{~m}$. Both fields were planted with an east-west row orientation and are drip irrigated. Vine shoots were trained to a quadrilateral cordon trellis at a height of $1.45 \mathrm{~m}$. While there is slight topography (0-2\% slope) the fields can mostly be characterized as a flat surface. The inter-row spaces are planted with a grass cover crop to regulate high spring-soil moisture conditions that accumulate during the winter season. Additional management practices performed in the vineyards include the timing and amount of drip irrigation, pruning activities, and application of agrochemicals; effectively, both vineyards were managed
Fig. 1 The location of study area is shown in the panels above. The northern (Site 1) and southern (Site 2) vineyards (left panel) are the vineyards of interest. The approximate locations of the $10 \mathrm{~m}$ micro-meteorological towers are represented by the yellow triangles. The micro-meteorological tower at Site 1 (center panel) and three panels (far right) show various stages of the production vineyard. (Color figure online)

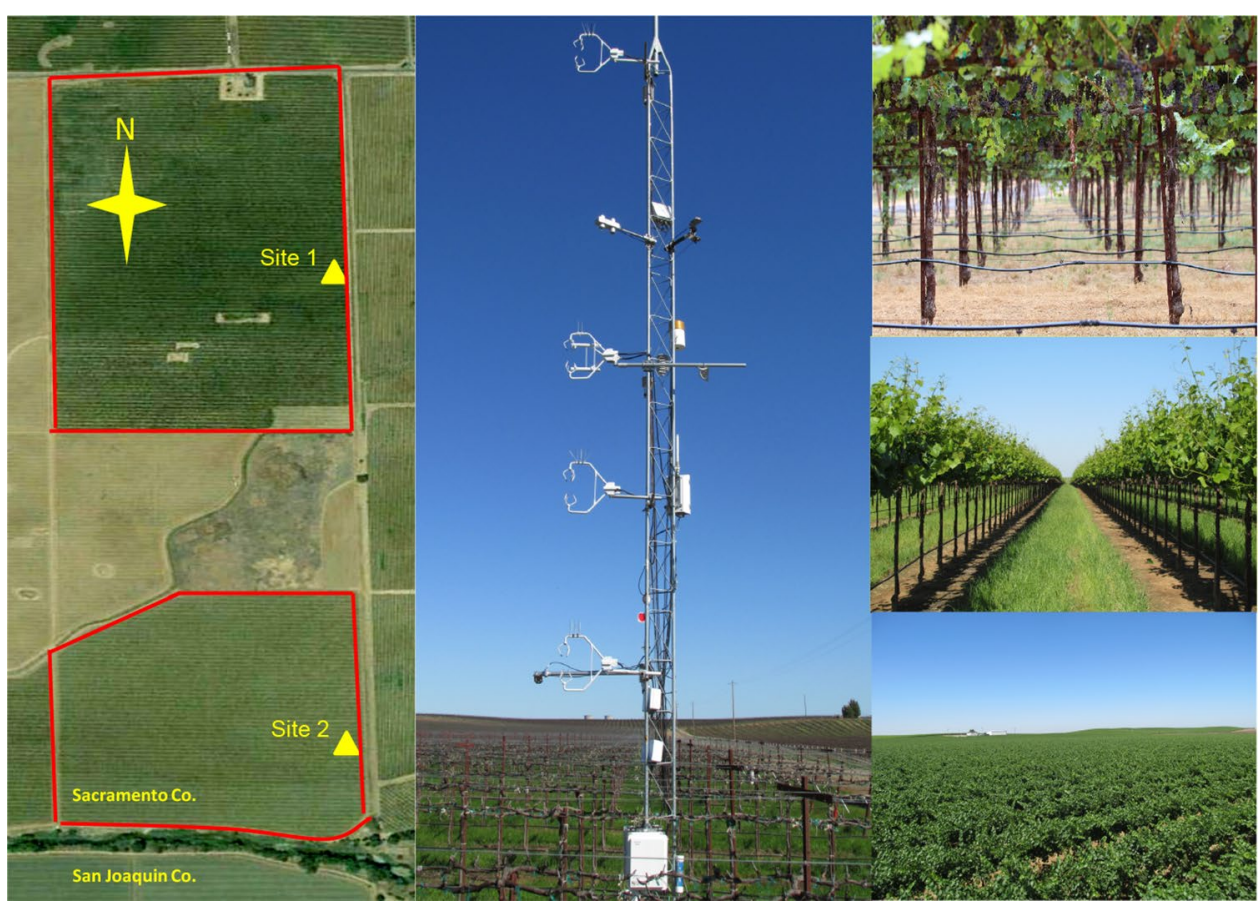


identically and the only significant difference was the age of the vines.

In this study we focused on three Intensive Observation Periods (IOPs) that were conducted in 2016. Each IOP represented 3 days of intensive measurement campaigns designed to capture multiple aspects of the objectives of the GRAPEx study. The IOPs for 2016 took place on the following dates: April 30-May 01 (IOP 1), June 10-12 (IOP 2), and July 27-29 (IOP 3). We further focused on IOP 3, which had conditions that were highly favorable to evaluating the CWSI, namely a fully developed canopy, local meteorological conditions conducive to promoting plant water stress such as strong radiation, high temperatures, and large vapor-pressure deficits. It should be noted that the near-surface local meteorological conditions during IOP 3 (July 27-29) were typical for this region and were similar to IOPs 1 and 2. By similar we mean that observed diurnal trends were nearly identical but varied somewhat in magnitudes of net radiation, temperature, wind speed, and vapor-pressure deficit. Additionally, it needs to be understood that the IOPs represent a very short time interval in which no management/ production activities were conducted on this privately owned vineyard. The IRT arrays were deployed only during the IOPs as by agreement with the ranch manager there would be no vineyard management operations. Thus the multi-IRT arrays were only put out during the IOPs and then removed at the end of the IOP so as to keep interference with normal production operations at a minimum. The EC towers were the only long-term continuous measurement made as the towers were erected in the middle of the vine rows and thus did not interfere vineyard operations.

\section{High-frequency eddy covariance instrumentation}

In 2013 the two study fields were instrumented each with a complete eddy covariance surface energy balance and wind profile system on identical $10 \mathrm{~m}$ radio towers. Winds at the study site tended to have a westerly component thus the towers were located on the eastern edge of both fields such that the dominant eddy covariance footprint for both towers were consistently within the target field boundaries for Sites 1 and 2.

The footprint or source area of eddy covariance measurements varies over time in response to changing surface and atmospheric conditions (Schmid 2002). To characterize the source area of the measurements, an analysis was conducted using the micro-meteorological data collected over a period of 3 years at Site 1 using the modified form of the Horst and Weil $(1992,1994)$ footprint model developed by Hsieh et al. (2000). Specifically, the flux footprint was calculated for each hourly period during the day (nominally 0600 to 1900 LST) for the months May through August during each year of the GRAPEX project (2013 to
2017). Based on the distribution of the results, the median and interquartile range of the upwind extent and orientation of the footprint was determined. Figure 2 shows a typical upwind extent of the footprint ranging between $44 \mathrm{~m}$ and $248 \mathrm{~m}$ with interquartile range of $63-123 \mathrm{~m}$. The median upwind extent of the five years of the study was $82 \mathrm{~m}$. The orientation of the footprint was consistently to the west; the footprint was oriented between $217^{\circ}$ and $312^{\circ}$ for nearly $95 \%$ of the measurement periods considered in this analysis. The interquartile range of the footprint orientation was between $247^{\circ}$ and $279^{\circ}$ with a median of $259^{\circ}$. Periods when the wind directions were outside of this range were not used in this analysis.

Turbulent energy fluxes for latent and sensible heat were measured via eddy covariance by collocating an infrared gas analyzer (IRGA) (EC-150 ${ }^{1}$, Campbell Scientific, Inc., Logan, UT) with the CSATA ${ }^{1}$ sonic anemometer at $5 \mathrm{~m}$ above ground level (AGL) on both towers. Sonic anemometer and IRGA sensors were oriented due west $\left(270^{\circ}\right)$ and sampled at a frequency of $20 \mathrm{~Hz}$. On each tower all highfrequency data were stored on a compact flash card (16 GB storage capacity) attached on a single CR3000 Campbell data logger that controlled all high-frequency instrumentation sampling rates and intermediate online computations. This configuration was adopted to ensure exact temporal synchronicity for high-frequency data acquisition involving all the sonics and IRGAs.

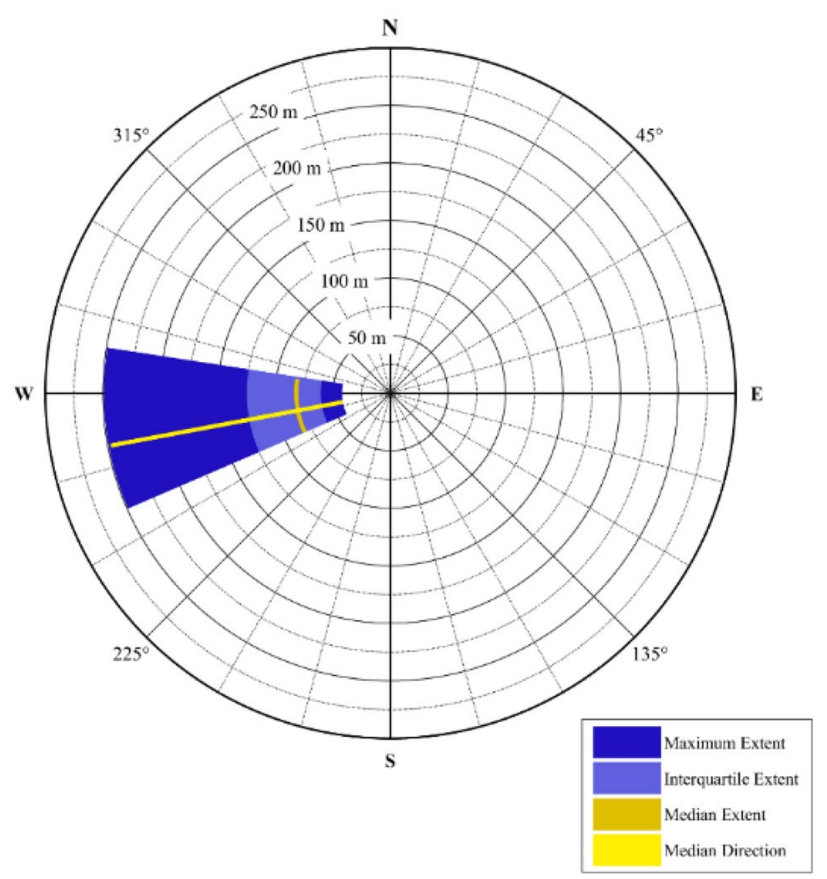

Fig. 2 The orientation and extent of the daytime footprint typical of the Borden site during the summer growing season 


\section{Eddy covariance data processing}

A more detailed explanation on high-frequency data processing for eddy covariance is provided by Alfieri, et al. 2018. Briefly, the eddy covariance data $(20 \mathrm{~Hz})$ were post-processed following a standard suite of micro-meteorological corrections. The averaged turbulent flux data were post-processed to account for effects of convective buoyancy and water vapor density (Webb et al. 1980; Lee et al. 2004, Burba and Anderson 2010). A two-dimensional coordinate rotation was applied to the wind velocity data so that the measurement coordinate system was aligned into the prevailing wind direction (Tanner and Thurtell 1969; Kaimal and Finnigan 1994). Sonic measured temperatures were transformed to actual air temperatures following the approach described by Liu et al. (2001). Finally the data were corrected for frequency response attenuation and sensor separation displacement (Massman 2001; and; Massman and Lee 2002).

\section{Low-frequency meteorological instrumentation}

Net radiation was measured with a four-component radiometer (CNR-1, Kipp and Zonen, Delft, Netherlands) mounted at $6 \mathrm{~m} \mathrm{AGL}$ and oriented toward the southwest. Additional auxiliary measurements for both towers included a vertical profile of a combination of humidity and air temperature sensors (HMP45C, Vaisala, Helsinki, Finland) mounted at 2.5, 3.75, 5 and $8 \mathrm{~m}$ AGL. Two thermal infrared thermometers (SI-111, Campbell Scientific Inc., Logan, UT, USA) mounted $2.5 \mathrm{~m} \mathrm{AGL}$, and a tipping bucket rain gauge (TE525, Texas Electronics, Dallas, TX, USA) at $3 \mathrm{~m}$ AGL. The low-frequency instrumentation were measured at $0.1 \mathrm{~Hz}$ and stored on a second CR3000 Campbell data logger.

\section{Soil heat flux and water content instrumentation}

Soil heat flux was measured and computed from an average of 5 soil heat flux plate transducers ( $G_{\text {plate }}$, HFT-3, Radiation Energy Balance Systems Bellevue, WA) deployed at a depth of $8 \mathrm{~cm}$ along a diagonal transect equidistant from each other beginning from 1 vine row across the inter-row space to the next vine row. Each soil heat flux plate was inserted with a pair of Type E (Chromel-Constantan) thermocouples located at 2 and $6 \mathrm{~cm}$ below the soil surface and above the soil heat flux plates. Soil-moisture sensors (HydraProbe, Stevens Water Monitoring System, Portland, OR) were collocated with each soil heat flux plate at a depth of $5 \mathrm{~cm}$ below the surface to measure soil water content for each $G_{\text {plate }}$ location. The soil moisture was then used in a post-process correction to the measured $G_{\text {plate }}$ data to include a computed soil heat flux storage $\left(G_{\text {storage }}\right)$ term in the soil layer directly above the $G_{\text {plate }}$; the storage term is added to the $G_{\text {plate }}$ to compute the final total soil heat flux estimate $\left(G_{\text {total }}=G_{\text {plate }}\right.$ $\left.+G_{\text {storage }}\right)$. Details for computing soil heat flux and soil heat flux storage are provided in Campbell and Norman (1998) and Ochsner et al. (2007). In addition to the intensive soil heat flux array a soil water content profile was installed underneath a vine row approximately $100 \mathrm{~m}$ southwest of the north surface energy balance tower. The soil water content profile was measured with three soil-moisture sensor probes (HydraProbe, Stevens Water Monitoring System, Portland, OR) installed at 30, 60 and $90 \mathrm{~cm}$ below the soil surface. The location of the profile measured the soil water content profile directly beneath the vine canopy and the drip irrigation emitters for the vine row but not the inter-row space in between vine rows which remained dry during the growing season. Volumetric soil water and temperature were recorded as hourly averages throughout the growing season.

\section{Vine canopy infrared sensor array}

Three stations were deployed in the northern vineyard to measure canopy temperature in areas of the vineyard with known varying degrees of vigor (North West, Center, and South East). Each station was instrumented with six thermal infrared thermometers (SI-111, Campbell Scientific Inc. Logan, UT) (Fig. 3). Two of these sensors were mounted approximately $1.0 \mathrm{~m}$ AGL each viewing the inter-row surface with a view angle of $44^{\circ}, 1$ to the north of the vine row and the other to the south. Two more sensors were mounted at mid-canopy height horizontal to the surface and perpendicular to the canopy row, one viewing the north side of the canopy and the other viewing the south side. Considerable care was taken to position the horizontally oriented sensors at the most densely vegetated portion of the vine canopy so as to ensure that no portion of the viewing angle included any contribution from the horizon. The remaining two sensors were placed above the canopy looking down at a nearnadir view, one angled slightly facing to the north and the other slightly to the south. All sensors were measured at $1 \mathrm{~Hz}$ (one time per second) and stored as 30-min averages on a CR21x (NW), a CR1000 (Center) and a CR10x (SE) Campbell Scientific data logger. For this study, only the infrared thermometers measuring the canopy temperature from the station in the center of the vineyard will be used for analysis. We selected this station for its close proximity $(\sim 50 \mathrm{~m})$ to the EC tower with all its ancillary surface energy balance measurements thus ensuring that this suite of measurements was well within the footprint of the EC system.

The target thermal infrared thermometers used in this study measure surface brightness temperature that are corrected for sensor body temperature. The procedure outlined in Blonquist et al. (2009) was used to compute the radiometric temperature used for CWSI calculations. This procedure computes radiometric temperature by correcting for canopy 
Fig. 3 General diagrammatic representation of multi-IRT placement over a single vine. Note the orientation of the IRT sensors. IRTs TC 3 and TC4 are more of top-down view of the canopy which can include information from the soil surface when the vine canopy is growing. IRTs TC1 and TC2 are of a horizontal view having minimal soil contribution

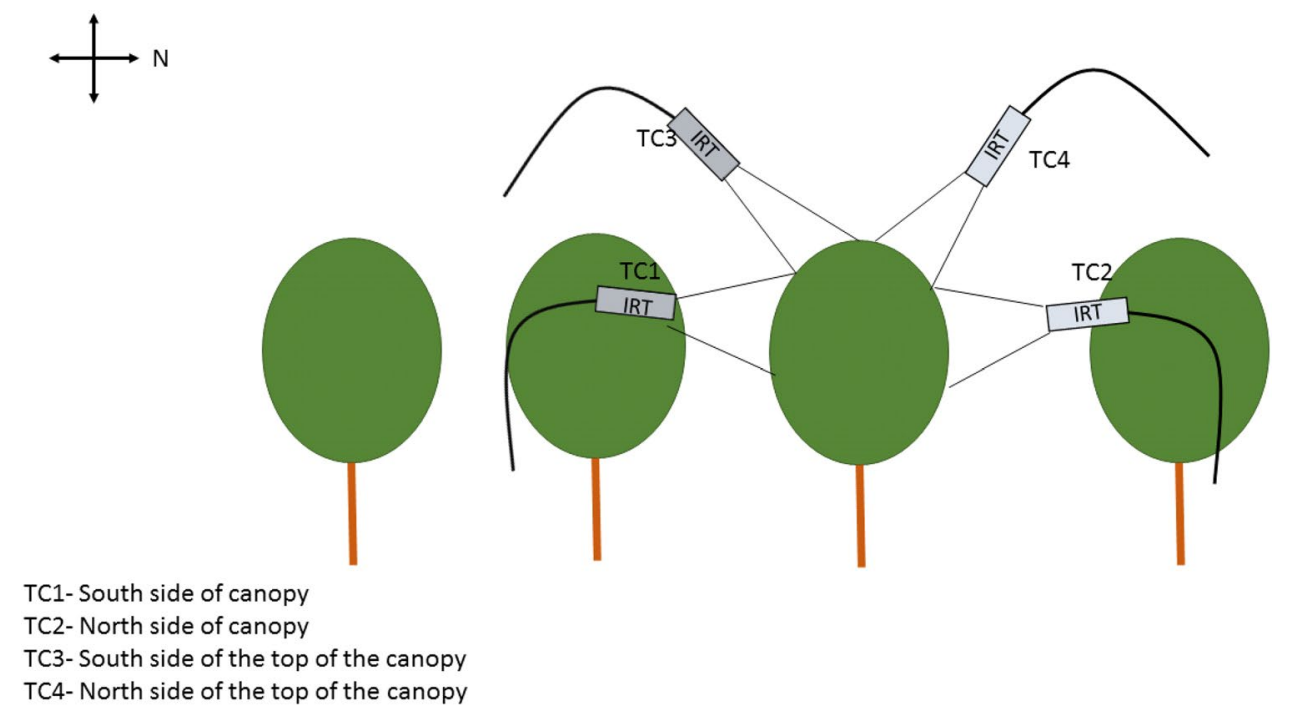

emissivity and background temperature. The emissivity of the vine canopy was estimated to be 0.99 (Blonquist et al. 2009) and the background temperature was computed from the incoming longwave radiation measured by the four-component radiometer. This method is believed to be a more accurate way of correcting for background temperatures and surface emissivity over a simpler and commonly used method of merely dividing the measured temperature by the emissivity, which does not account for the reflected background radiation.

Where this study focused on solely the canopy temperature rather than a composite of soil and canopy temperature to compute the Crop Water Stress Index, it was decided that an estimate of net canopy radiation be used in place of the surface net radiation measured at the flux tower. Using inputs of surface radiometric temperature, leaf area index, and radiative forcing, the Two Source Energy Balance model (TSEB) was used to compute the soil and canopy energy balances separately (Nieto et al., this issue). To address the hedgerow spatial distribution of the vine canopy for shortwave radiation transmission, a clumping index for rectangular hedgerow was used with the Campbell \& Norman transfer model (Parry et al., this issue). Doing so provided an estimate for net radiation of the vine canopy which was used in Eqs. 2 and 3 to calculate the upper and lower limits.

\section{Results}

During IOP 3, winds were mild and variable (Fig. 4a) with convectively generated wind speeds during the daytime hours followed by low winds in the early evenings lasting through the night and into the morning. Air temperatures were strongly diurnal ranging from approximately $16-37{ }^{\circ} \mathrm{C}$ which contributed to large vapor-pressure deficits (Fig. 4b, c). Measured net radiation (Fig. 4d) indicates clear sunny days contributing to an abundance of radiant energy to be partitioned into turbulent fluxes of $\lambda E, H$ and soil heat flux $G$. Vertical lines centered through the peak $R_{n}$ values were drawn to highlight an important feature that occurred during IOP 3 (July 27-29) as well as during IOPs 1 and 2 (Figs. not shown for IOP $1 \& 2$ ). A clear temporal lag with respect to $R_{n}$ for air temperature and VPD can be observed to increase significantly throughout the early afternoon hours until about $1600 \mathrm{~h}$ after which the $T_{a}$ and VPD trends begin to rapidly decrease into the early evening hours. Increasing $T_{a}$ and VPD after peak $R_{n}$ are common in semi-arid regions and represent contributing surface meteorological and environmental conditions that can promote plant water stress.

Figure 5a-c shows volumetric soil water content (VWC) for the soil-moisture profile for each day of IOPs 1-3. Typical VWC-values for the Kimball silt loam at field capacity can range from 0.25 to 0.4 percent volumes (USDA Soil Conservation Service 1993b). During IOP 1, VWC for the $30 \mathrm{~cm}$ depth was over 0.30 on April 30 and gradually decreased to approximately 0.28 by May 03 . The $60 \mathrm{~cm}$ depth was just below 0.30 and remained relatively constant throughout the 3-day period. This static trend occurred at the $90 \mathrm{~cm}$ depth as well with a VWC of about 0.32 . We consider the VWC for IOP 1 to be somewhere near the midrange of field capacity for this type of silt loam. In general, a slight decrease in VWC is observed over the 3 days at the $30 \mathrm{~cm}$ depth with little-to-no change at the 60 and $90 \mathrm{~cm}$ depth. Vine vegetation during May 01-April 30 had emerged by this time but was still nascent. Drip irrigation of these vines had not yet commenced at this early stage since the vines were relying on soil water that had accumulated during the previous winter precipitation. Figure $5 \mathrm{~b}$ shows that by IOP 2 (June 10-12) the soil water profile had significantly changed since IOP 1 . Drip irrigation events tended to 
Fig. 4 a-d Meteorological conditions for IOP 3 (July 27-29). Wind speed (a), air temperature (b), vapor-pressure deficit (VPD) (c) and net radiation, $R_{\mathrm{n}}$ (d). Note that decimal day-ofyear (DOY) represents the DOY and the fraction of time for the DOY

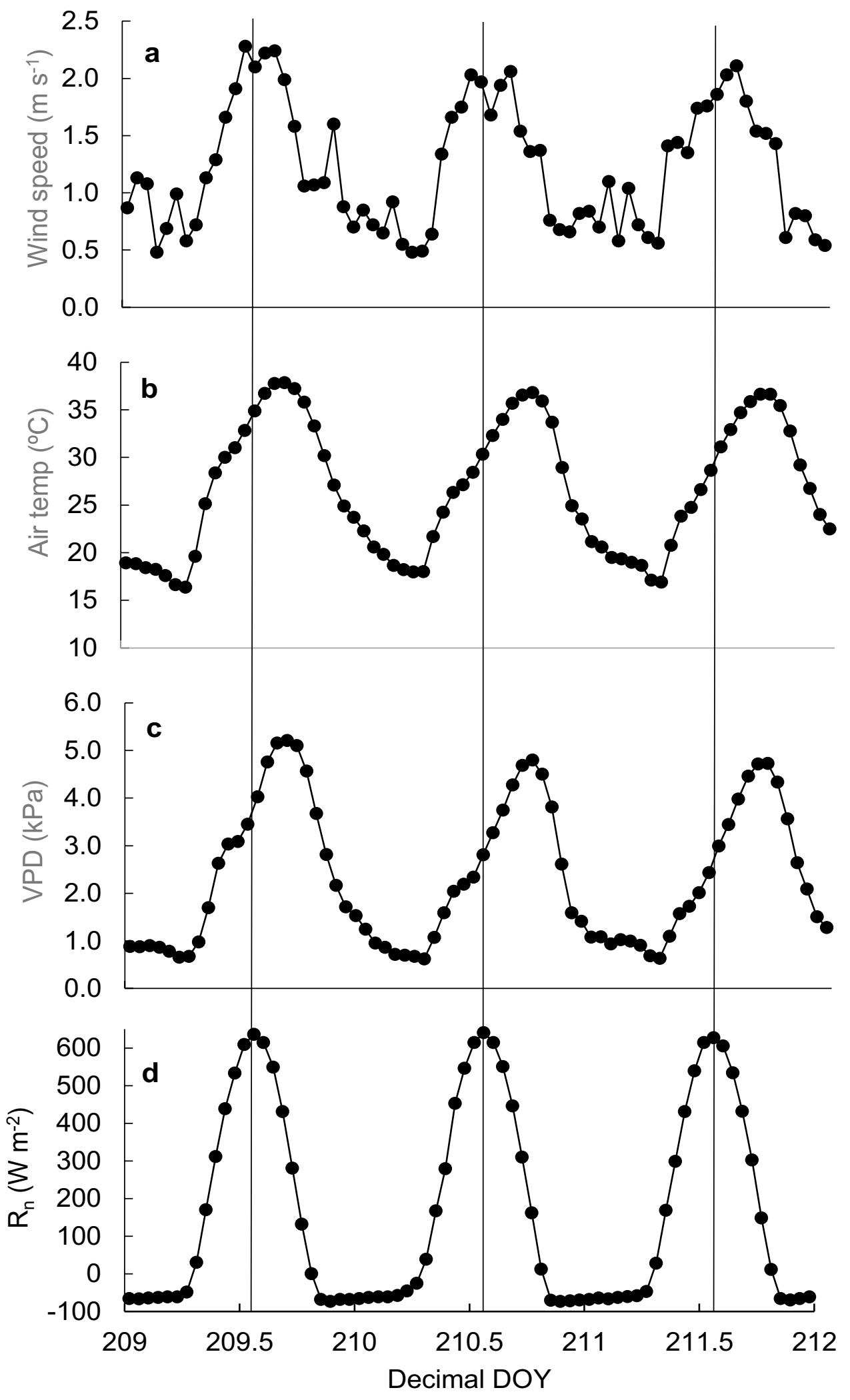

commence in the late (1100-1200 h) morning reaching peak VWC-values after mid-day on June 10 and 11 . No irrigation took place on the June 12 and as a result the VWC profile underwent a rapid depletion through June 13 indicating a strong dynamic response integrating the vine canopy, VWC of the soil profile and the local meteorological conditions of 
Fig. 5 a-c Soil volumetric water content (VWC) at three depths directly underneath a vine row within the study block. The VWC time trace represents each of the three days for each IOP $1-3$ in 2016. The striped boxes represent the period of 6:00-20:00 each day
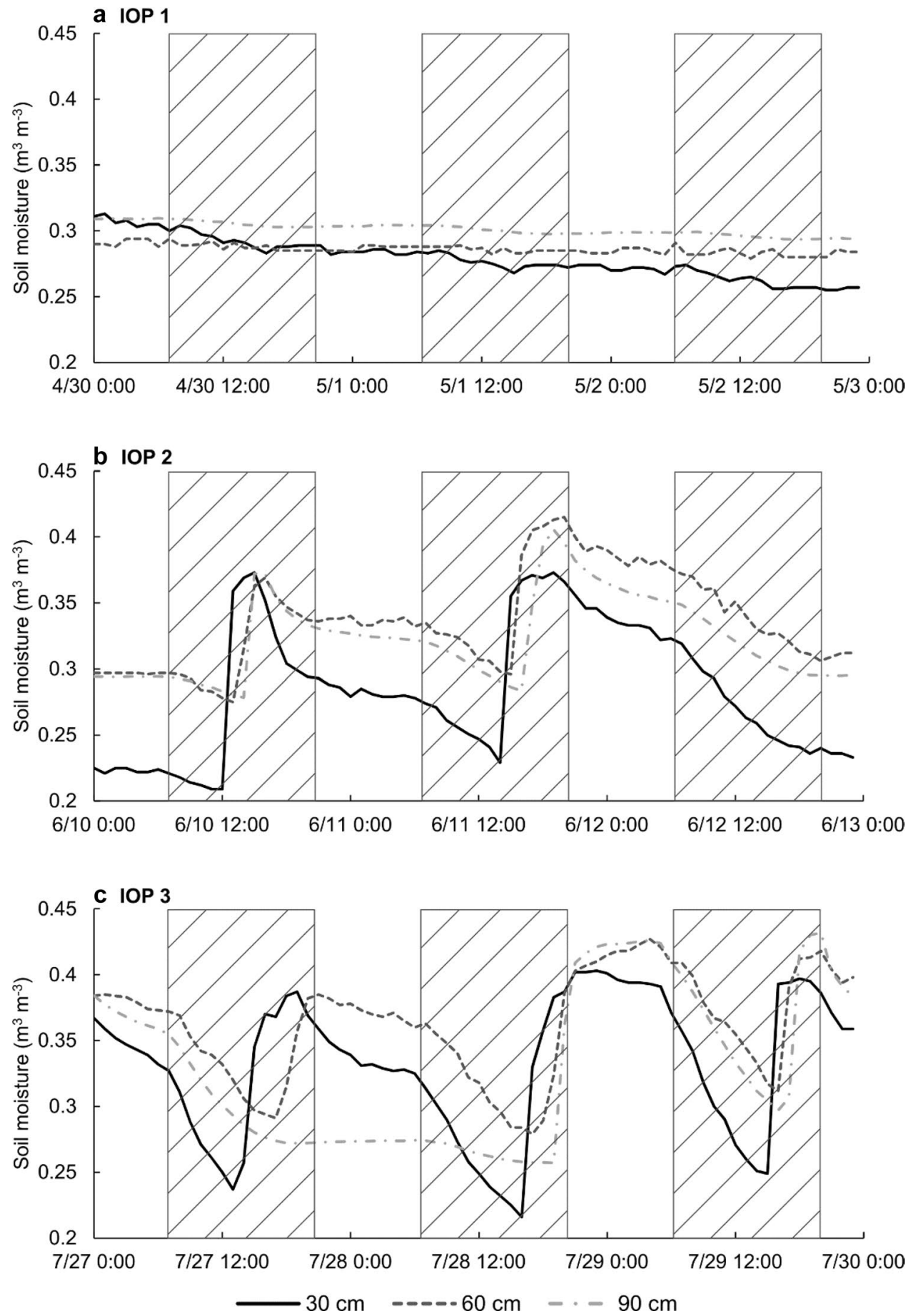

warm temperatures and large VPD. During IOP 3, 3 irrigation events are observed on July 27, 29, and 30. We observed that for IOPs 2 and 3 the VWC at $60 \mathrm{~cm}$ tended to be slightly greater than the $90 \mathrm{~cm}$ depth. We are not sure what caused this unexpected feature but remain confident that the signature wetting and drying cycles were well-correlated for all three depths. For the purpose of investigating plant water stress, the VWC profile measurements indicate that the soil beneath the vine canopy was well watered during the IOPs.
During times of irrigation, soil profiles would recharge rapidly suggesting that the soil water profile during the IOPs were near field capacity which together with the silt loam texture resulted in a high infiltration rate. This was particularly evident at the $30 \mathrm{~cm}$ depth while at the lower depths of 60 and $90 \mathrm{~cm}$, diurnal wetting and drying cycles were also observed suggesting that the entire approximately $1 \mathrm{~m}$ depth was actively involved in the plant water uptake of the vines. In general, this is consistent with the dominant portion of the 
vine root mass to be in the upper $1 \mathrm{~m}$ soil depth but there are roots that extend deeper below 1.5-2 $\mathrm{m}$ (unpublished data).

Figure $6 a-c$ shows the $\lambda E$ and $H$ eddy covariance fluxes for the 3 days during IOPs 1-3. Latent heat fluxes during IOP 1 (Fig. 6a) were lower than those during IOP 2 and 3 (Fig. 6b, c) as was expected given the condition of a new vine canopy developing in late April and early May with cooler temperatures. Maximum $\lambda E$ fluxes peaked around
$275 \mathrm{~W} \mathrm{~m}^{-2}$ compared to the maximum $\lambda E$ fluxes in June and July which were in excess of $400 \mathrm{~W} \mathrm{~m}^{-2}$. Sensible heat fluxes were largest during IOP 1 and steadily decreased in peak magnitude with each IOP (mid-range $H$ in IOP 2 and lowest $H$ fluxes in IOP 3 ) as the growing season progressed. This trend is consistent with a vine canopy that is increasing in volume as well as cover over the inter-row space, intercepting more solar radiation, and thus less solar
Fig. 6 a-c $\lambda E$ and $H$ for IOP $1-3$. Note that decimal day-ofyear (DOY) represents the DOY and the fraction of time for the DOY
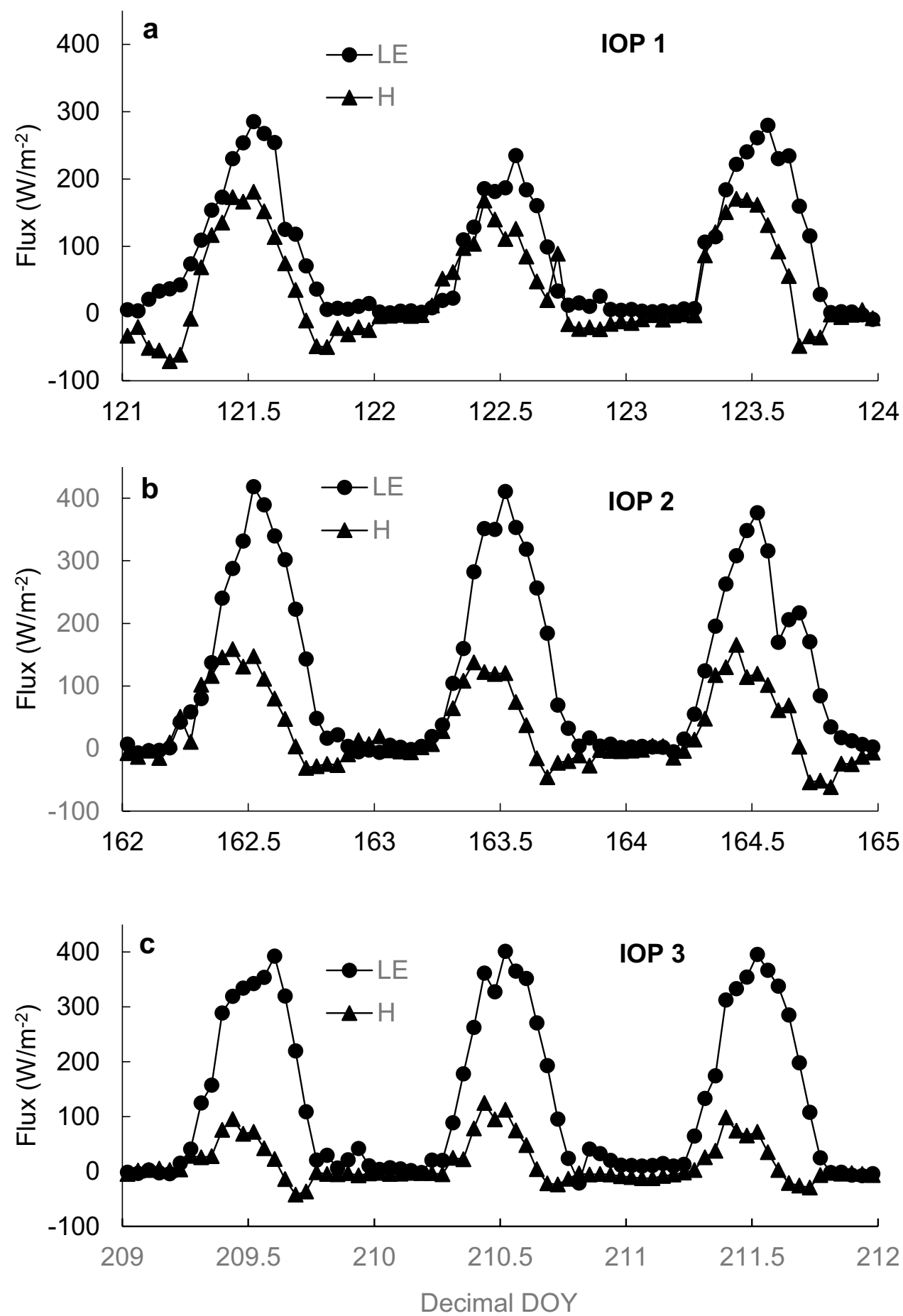
impingement onto the soil resulting in reduced soil surface heating. Additionally a noticeable temporal lag of $H$ to $\lambda E$ occurs with maximum $H$ values in the late morning hours. This becomes evident on the second day of IOP 1 and remains throughout the growing season. This is most likely related to the rapid growth period in early May. During all three IOPs there is evidence of advection of VPD (negative $H)$ in the late afternoon periods contributing to increased $\lambda E$ fluxes (higher ET) as well as the potential for plant water stress.

The reliability of the surface energy flux measurements was evaluated by plotting the closure of the four measured surface energy balance components as the sum of turbulent heat fluxes $(\lambda E+H)$ against the available surface energy $\left(R_{\mathrm{n}}-G\right)$ shown in Fig. 7. The data used for this evaluation were from 0800 to $1600 \mathrm{~h}$ for each of the three consecutive days of each IOP. This time period ensured that we met the requirement of $\left(R_{\mathrm{n}}-G\right)>100 \mathrm{~W} \mathrm{~m}^{-2}$ to avoid uncertainties for the turbulent fluxes typically associated with transitioning stability periods, from unstable to neutral to stable and then again in reverse (stable to neutral to unstable), as well as avoiding periods with friction velocities $\left(u^{*}\right)<0.1 \mathrm{~m} \mathrm{~s}^{-1}$. The average closure ratio $(\lambda E+H) /\left(R_{\mathrm{n}}-G\right)$ for all periods during the IOPs was 0.84 indicating a high level of confidence in the quality of the turbulence heat flux data as this closure ratio is well within the range of many reported literature closure ranges (0.68-0.92). Perfect closure (unity) rarely occurs in any environment, native or agricultural. Reasons for lack of closure can be found in Aubinet et al. (2000) and Wilson et al. (2000).

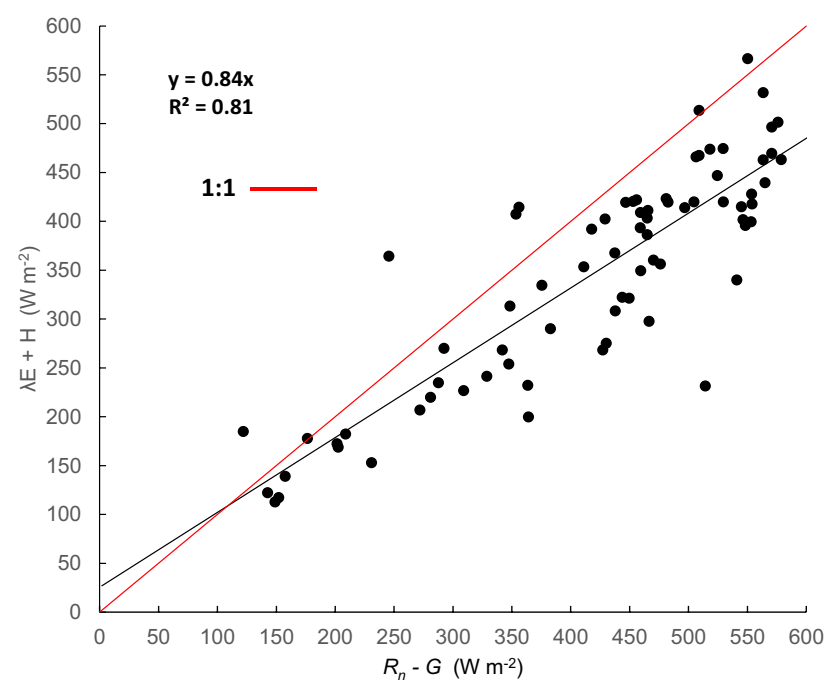

Fig. 7 Sum of the turbulent latent and sensible heat fluxes $(\lambda E+H)$ evaluated against the available energy $\left(R_{\mathrm{n}}-G\right)$. 1:1 line represents perfect closure. Turbulent fluxes and available energy points were calculated using 08:00-16:00 hourly averages of the surface energy balance components $\left(R_{\mathrm{n}}, G, \lambda E, H\right)$ for each of the three days for IOP $1-3$ in 2016
Figure 8a-f shows diurnal values of the average canopy temperature $\left(T_{\mathrm{c}}\right)$ and the average canopy-air temperature difference $\left(T_{\mathrm{c}}-T_{\mathrm{a}}\right)$ for a single day for each of the three IOPs. Diurnal canopy temperatures for IOP 1 and 2 were similar to each other while the canopy temperatures for IOP 3 were higher for each hour of the day compared to IOPs 1 and 2. For IOPs 2 and 3 the canopy temperature goes below air temperature earlier in the day than it did for the previous IOP. Canopy temperature is overall lower in the afternoon for IOPs 2 and 3 compared to the previous IOP with canopy temperatures during IOP 3 being the lowest of all three IOPs. One of the first indicators of canopy stress is a positive or small negative canopy-air temperature difference. The canopy-air temperature differences observed in Fig. $8 b$, d, f suggest that the vine canopies are actually becoming less stressed in the afternoon and less stressed as VPD increases. Canopy stress is often observed at its peak after solar noon when VPD and air temperature were at their highest; this is more pronounced when soil water availability is low. Vapor-pressure deficit values were similar for IOPs 1 and 2 while the VPD for IOP 3 was larger as expected as the season progressed with warmer and drier conditions (Fig. 9). The measured canopy minus air temperature $\left(T_{c}\right.$ - $T_{\mathrm{a}}$ ) is plotted against the CWSI upper (water-stressed) and lower $T_{\mathrm{c}}-T_{\mathrm{a}}$ baselines (non-stressed) in Fig. 10. For each IOP the measured $T_{\mathrm{c}}-T_{\mathrm{a}}$ follows the upper line in the morning and begins to diverge just before noon. As the day progresses, the difference between the upper and measure lines increases. The upper and lower baselines are very similar for all three IOPs while the measured $T_{\mathrm{c}}-T_{\mathrm{a}}$ for each IOP is generally lower than the previous IOP.

The CWSI is considered a more fundamental indicator of canopy stress than the canopy-air temperature difference as it considers the energy balance of the canopy layer. The CWSI values observed in Fig. 11 support the earlier indication that the canopy is becoming less stressed even as the $T_{\mathrm{a}}$ and VPD were continually increasing from midday to about $1600 \mathrm{~h}$. This is contrary to what is typically seen with crop stress increasing for most crops under high radiation, $T_{\mathrm{a}}$ and VPD loading. This increased stress is most often due to the inability of a crop to keep up with transpiration demands of the environment due to lack of adequate available soil water. The left graphs in Fig. 10a, c, e show the CWSI calculated for each individual IRT canopy temperature at their respective viewing angle and orientation. Overall, the CWSI values derived from the IRT sensors viewing the south-facing side of the canopy $\left(T_{\mathrm{c} 1}\right.$ and $\left.T_{\mathrm{c} 3}\right)$ were higher than those calculated from the IRTs viewing the north-facing side of the canopy $\left(T_{\mathrm{c} 3}\right.$ and $T_{\mathrm{c} 4}$ ). This is what would be expected since the south-facing canopy would receive more sunlight and thus have warmer leaves than the north-facing canopy. The average CWSI from all four CWSI sensors (right side of Fig. 11b, d, f) is 

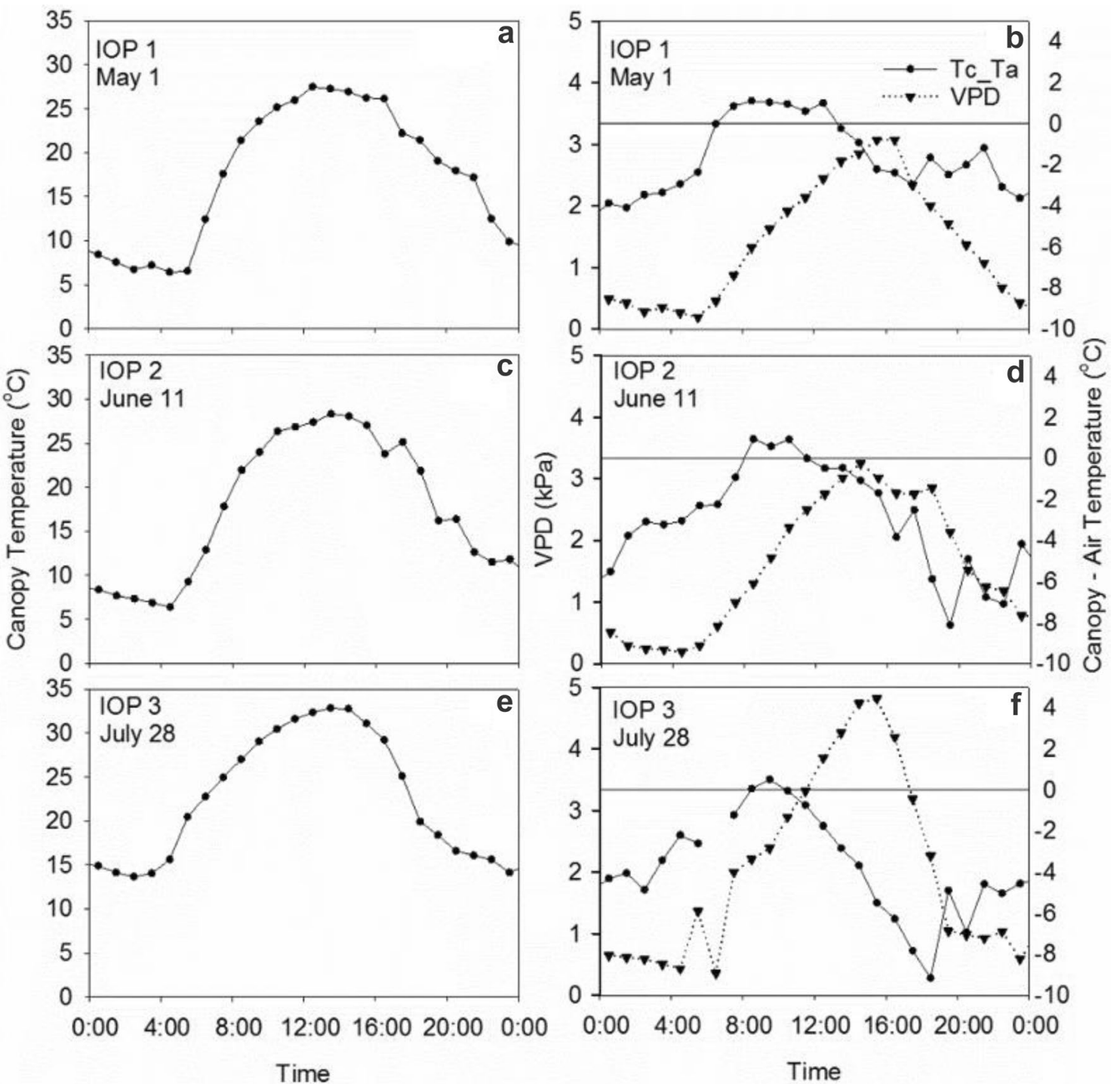

(right side) for IOPs 1-3 (IOP 1, a, b, IOP 2, c, d, IOP 3, e, f)

likely to give a more accurate representation of the whole canopy due to incorporating multiple canopy view angles and thus multiple leaves at varying leaf angles, sunlight exposure and temperatures.

The temporal downward trend of the CWSI observed in Fig. 11 is interesting in that local meteorology observed in Fig. 4a-e, in particular Fig. 4b, c, shows conditions that could promote plant water stress. While the range of the CWSI values appeared to suggest that those conditions were present (e.g., hot air temperatures, strong vapor-pressure deficit, clear sky radiation and moderate mean wind speeds) the large $\lambda E$ fluxes shown in Fig. 6a-c suggested low-to-no water stress conditions. To investigate this result, we computed the Bowen ratio $(\beta)$ using the turbulent flux data measured with eddy covariance for the middle day of the three IOPs to coincide with the time range of the CWSI plots in Fig. 11.

The Bowen ratio (Bowen 1926) is the ratio of sensible-tolatent heat flux $(H / \lambda E)$ and is indicative of the partitioning of the available energy between sensible and latent heat, or one may consider the evaporative potential of the surface. During daytime conditions, large $\beta$ values are associated with most of available energy of the surface converted to sensible heat flux (low ET) and conversely small or negative $\beta$ values are associated with most or all of the available energy plus advected heat (when $\beta<0$ ) converted to latent heat (near or at potential ET). Figure 12 shows the $\beta$ values for the middle day of each IOP, where in general we observe a similar decreasing CWSI trend shown in Fig. 10. Exceptions to this trend in $\beta$ were observed for the CWSI at the end of the 


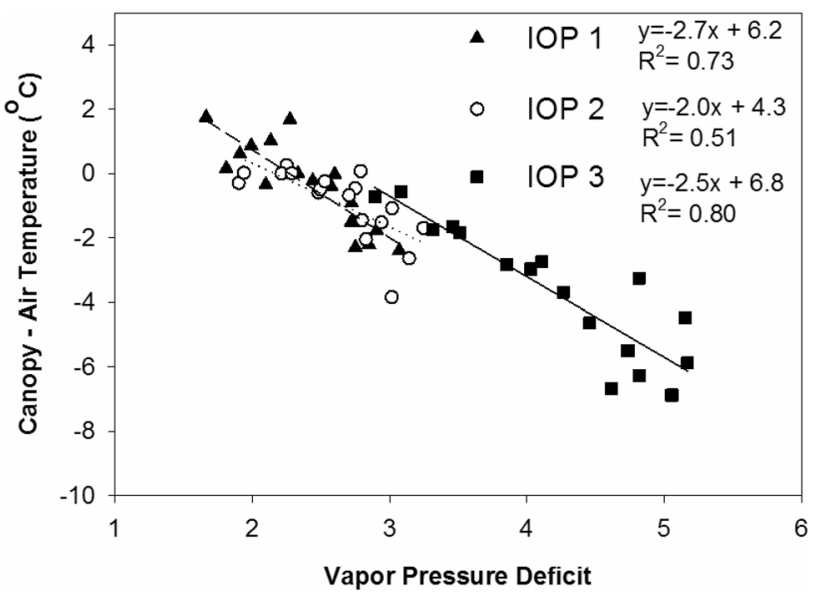

Fig. 9 Canopy-air temperature difference vs vapor-pressure deficit for IOP1, IOP2, and IOP3

period for IOPs 1 and 2. In IOP 1 , a significant drop in $\lambda E$ was observed at about $1600 \mathrm{~h}$, while in IOP $2 \mathrm{H}$ had become negative (heat advection) at around $1500 \mathrm{~h}$ adding more heat to the vines during strong late afternoon heating, potentially causing $\lambda E$ to decrease due to stomata response from the increased heating from advection. When we evaluated CWSI for the other days of the 2016 IOPs (data not shown) they showed the same decreasing temporal trend with $\beta$ highest in the morning and lowest in the late afternoon. The results in Fig. 12 confirm that much of the available energy as well as large VPD was converted to latent heat flux of ET during the IOPs and in fact during much of the mid-to-late growing season during the afternoon periods. Decreasing $\beta$ coupled with near field capacity VWC shown in Fig. 3a-c suggest that while strong atmospheric demand appeared to favor vine stress, the abundance of available soil water allowed for large transpiration rates resulting in a net "cooling" effect of the canopy. This cooling resulted in a decreasing trend of CWSI during the most stress prone conditions of the day.

\section{Discussion}

We were at first puzzled about the CWSI results that clearly show a decreasing stress trend under meteorological conditions that would suggest increasing plant water stress. We did not expect this outcome largely because we were considering the impact of strong radiation with a large VPD on a vineyard and not necessarily the impact of soil water content and its role in the soil-plant-continuum. Our results caused us to carefully re-evaluate all of our computations multiple times using several different approaches but always ending up with the same result, decreasing CWSI during the afternoon periods. One plausible explanation based purely on our measurements is to carefully consider the

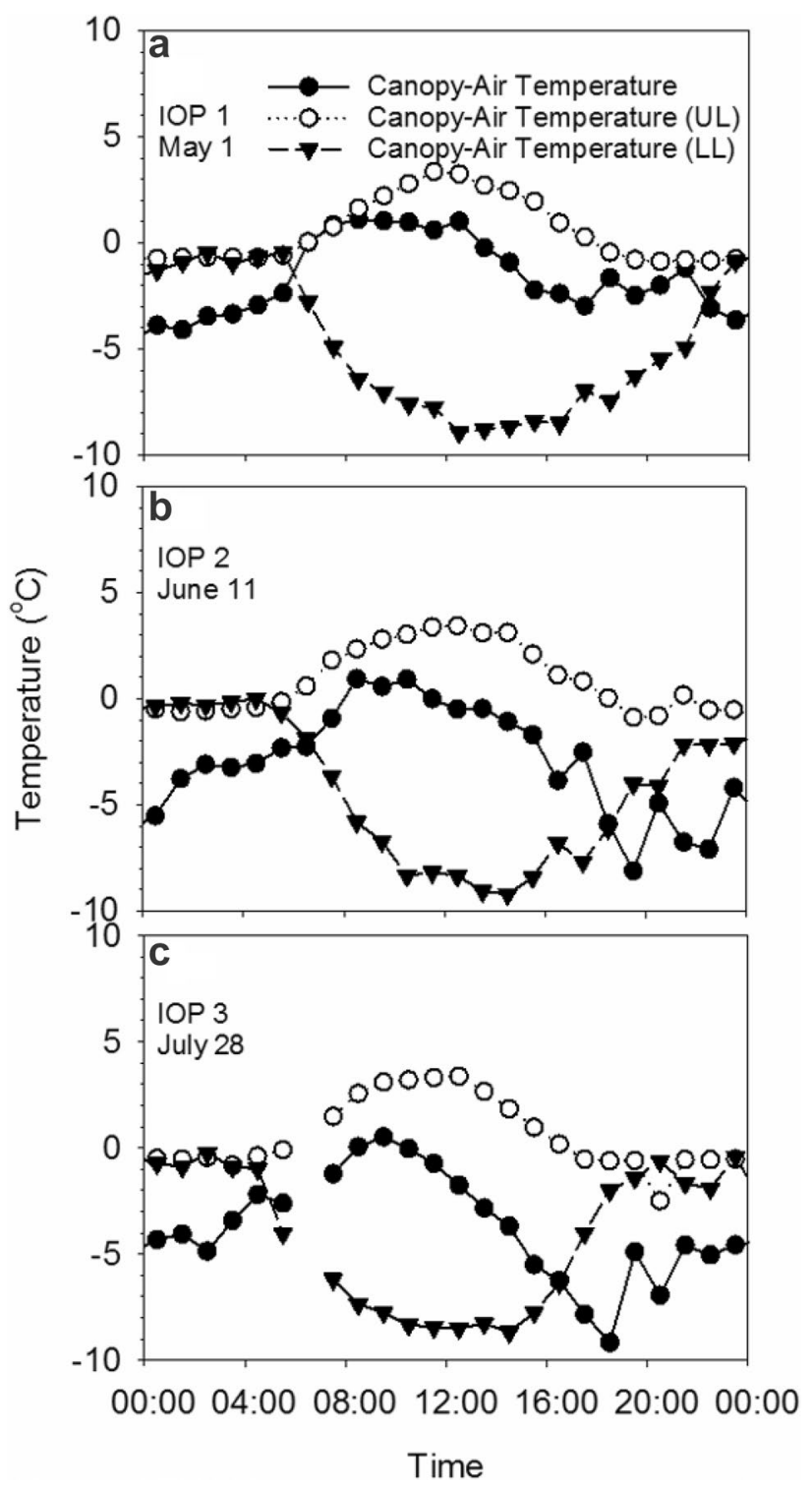

Fig. 10 a-c Canopy-air temperature differences, using average canopy temperature, plotted with the theoretical upper (UL) and lower (LL) limits of the CWSI

soil-plant-atmosphere continuum. In this study the soil water content measurements always indicated substantial available water, there was no shortage of soil water but rather an abundance as evidenced by simple observations in many areas across the vineyard where directly beneath the drip lines, moss was observed to be growing on the soil surface and this under semi-arid conditions. This anecdotal evidence is indicative of a long-term wet soil surface condition. The vine canopy was healthy, vigorous and well-coupled to the hot dry (large VPD) surface layer atmosphere above the canopy and with an abundance of solar radiation, had all of the requisite elements for high ET rates which is supported by the large EC latent heat flux values observed in our study. We 

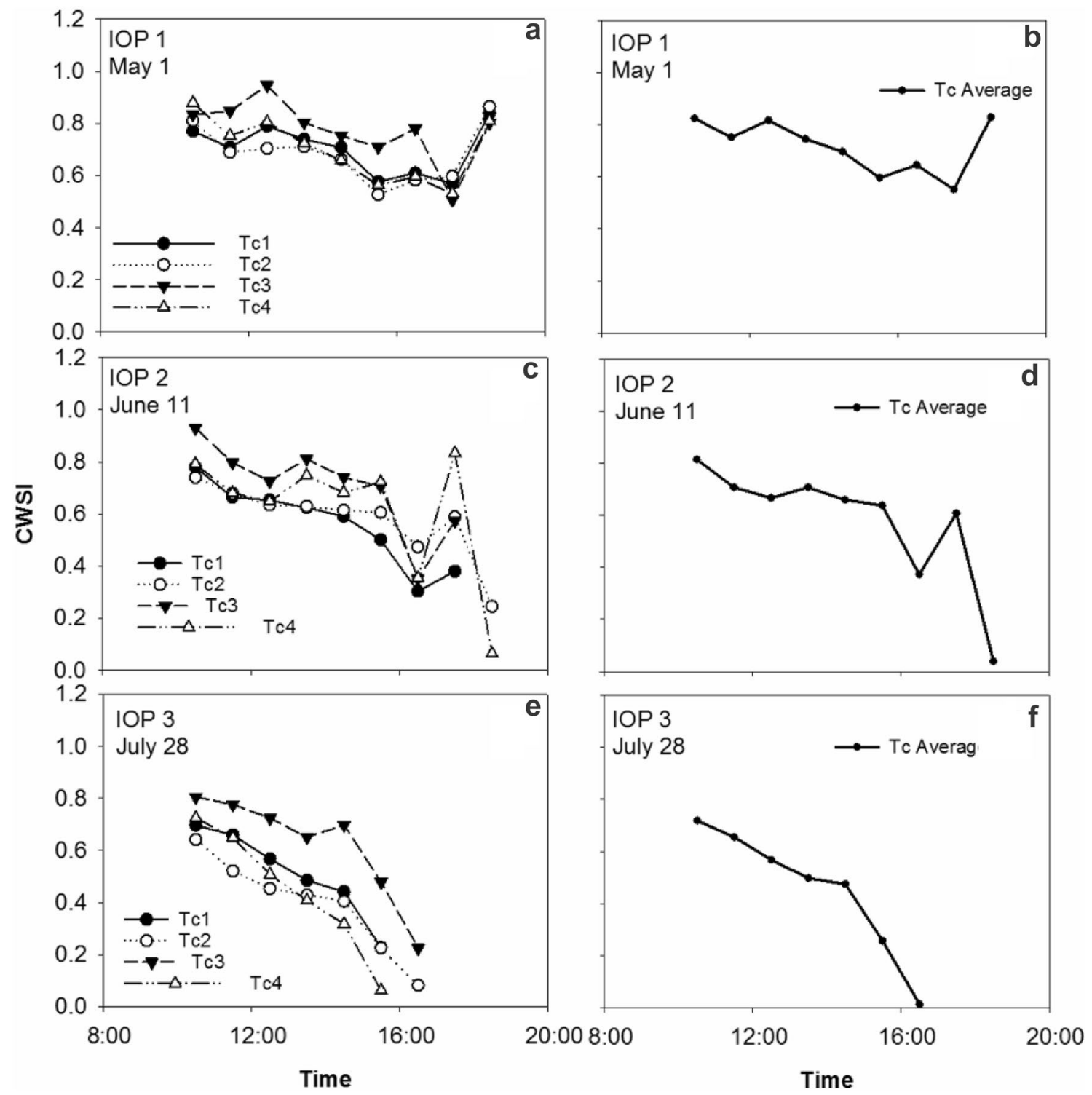

Fig. 11 a-f Crop Water Stress Index (CWSI) vs day and time for IOP1 (a, b), IOP2 (c, d) and IOP3 (e, f)

did not consider fully the impact of the soil water content and how it is the basic source of water for evapotranspiration for the soil-plant-atmosphere continuum. Our results clearly showed VWC in soil $(30-90 \mathrm{~cm})$ to be near or at field capacity during the IOP's and throughout the growing season which was maintained by continual recharging of the soil water profile via drip irrigation. We speculate that there was stomatal response (partial stomatal closure) due to the hot dry import of VPD but because there was no limitation of soil water per se, the vine vegetation continued to transpire at a high rate. Thus the explanation for our results is related to the strength of the coupling of the soil-vegetation-atmosphere continuum, substantial available soil water, and healthy vine canopy supported by dense root mass, large VPD and radiation energy. More analysis needs to be conducted at different locations in the vineyard but also under conditions of lower soil water content. The potential implications of our results for irrigation management strategies are if the CWSI shows a strong decreasing trend in the afternoon periods under surface meteorlogical conditions that would indicate plant water stress then perhaps reduced irrigations could be imposed resulting in water and monetary savings.

\section{Conclusions}

The CWSI method as applied to a vineyard in the Central Valley of California produced results that were consistent with the observed local conditions of the vineyard. During 


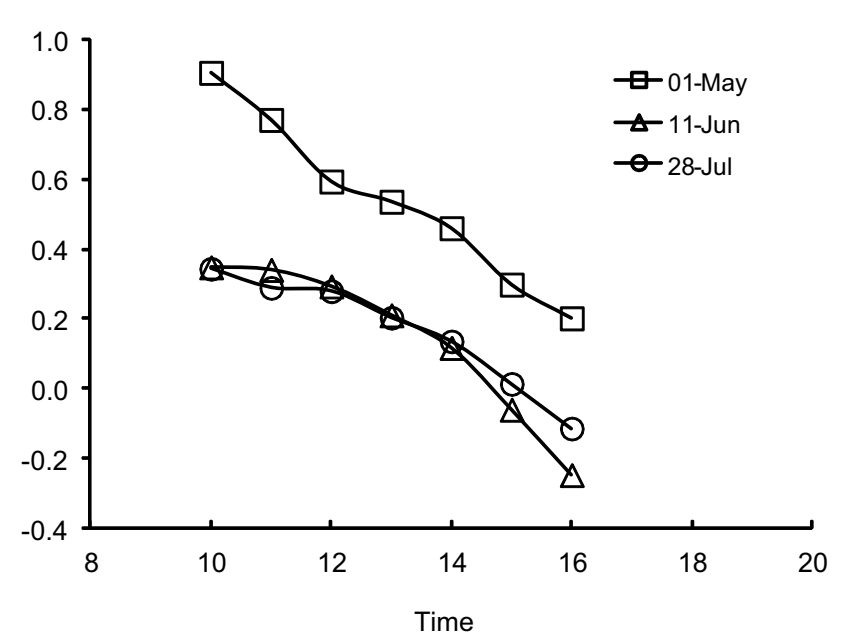

Fig. 12 Bowen-ratio time series $(1000-1600 \mathrm{~h})$ computed from measured eddy covariance $H$ and $\lambda E$ for the middle day of each IOP in 2016

all IOP cases, CWSI values were in general higher in the mid-to-late morning periods and then gradually decreased into the afternoon periods. This morning to afternoon trend suggests decreasing stress conditions for the vines during all three IOP's. Bowen-ratio $(H / \lambda E)$ values followed a similar trend due to increasing evapotranspiration rates and a concurrent decrease in $H$, indicating more of the available energy $\left(R_{n}-G\right)$ was being converted to latent heat flux. The decreasing Bowen-ratio trend during the hot afternoon periods support the similar decreasing trend of the CWSI albeit unexpected but completely rational as supported by the relatively high soil VWC maintained throughout much of the growing season for this vineyard. Collectively, the results from this study suggest that maximum water availability for this vineyard was maintained throughout most of the critical vine and grape production periods. While the derivation of the CWSI implies a method to compute plant water stress, our results show that the CWSI can reliably provide information of decreasing or lack of plant water stress suggesting that perhaps a more appropriate name for the CWSI could be crop water status index. Additionally, multiple view angle IRT measurements of the vine canopy showed distinct canopy temperature variations depending on the orientation (side or top-down view) and direction (north vs south canopy sides) of the IRT sensors. This variation invariably translates to variations in the magnitude of the CWSI but in this study not the decreasing trend observed during the IOP's. This begs an important and fundamental question regarding how best to locate ideal positions to view a vine canopy as it has considerable implications for airborne and satellite-mounted thermal sensors and the specific view angles that these sensors acquire surface temperature measurements from. Considerably more effort is needed to address this question.

Acknowledgements We recognize the considerable contributions scientists and technicians and students from the Viticulture, Chemistry and Enology Division of the E\&J Gallo Winery for the tremendous collaboration, collection, and processing of field data during each of the IOPs conducted at the Borden/McMannis vineyard site. We extend our heartfelt gratitude for cooperation provided by Mr. Ernie Dosio of Pacific Agri Lands Management as well as the help and generosity of the entire Borden/McMannis vineyard staff for their continued cooperation as well as the invaluable logistical support of the GRAPEx research activities. USDA is an Equal opportunity provider and employer.

\section{References}

Alfieri JA, Kustas WP, Nieto H, Prueger JH, Hipps LE, McKee LG, Gao F (2018) Influence of wind direction on the surface roughness of vineyards. Irrig. Sci. (this issue)

Aubinet M, Grelle A, Ibrom A, Moncrief J, Foken T, Martin P, Berbigier P, Bernhofer CH, Clement R, Elbers J, Granier A, Grunwald T, Morgenstern K, Pilegaard P, Rebmann C, Snijders W, Valentini R, Vesala T (2000) Estimated of the annual net carbon and water exchanges of European forests: the EUROFLUX methodology. Adv Ecol Res 30:113-174

Bellvert J, Marsal J, Girona J, Zarco-Tejada PJ (2014) Seasonal evolution of crop water stress index in grapevine varieties determined with high-resolution remote sensing thermal imagery. Irrig Sci. https://doi.org/10.1007/s00271-014-0456-y

Bellvert J, Marsal J, Girona J, Gonzalez-Dugo V, Fereres E, Ustin SL, Zarco-Tejada PJ (2016) Airborne thermal imagery to detect the seasonal evolution of crop water status in peach, nectarine and Saturn peach orchards. Remote Sens 8:39-56

Berni JAJ, Zarco-Tejada PJ, Suárez L, Fereres E (2009) Thermal and narrowband multispectral remote sensing for vegetation monitoring from an unmanned aerial vehicle. IEEE Trans Geo Remote Sens 47(3):722-738

Blonquist JM, Norman JM, Bugbee B (2009) Automated measurement of canopy stomatal conductance based on infrared temperature. Agric For Meteorol 149:2183-2197

Bowen IS (1926) The ratio of heat losses by conduction and by evaporation from any water surface. Phys Rev 27:779

Bramley RGV (2005) Understanding variability in wine grape production systems 2 . Within vineyard variation in quality over several vintages. Austral J Grape Wine Research 11:33-45

Bramley RGV, Lanyon DM (2002) Evidence in support of the view that vineyards are leaky-indirect evidence and food for thought from precision viticulture research. In: Bramley RGV and Lanyon DM (Eds) 'Vineyard 'leakiness' Proceedings of a workshop held at the Waite Campus, Adelaide, 24-25 January, 2002, to scope the potential threat to the sustainability of Australian viticulture through excessive drainage below the root zone. Final Report on GWRDC Project No. GWR01/04. CSIRO Land and Water/Grape and Wine Research and Development Corporation, Adelaide

Burba G, Anderson D (2005) A brief practical guide to Eddy covariance flux measurements: principles and workflow examples for scientific and industrial applications. LI-COR Biosciences, Inc

California Department of Food and Agriculture \& USDA National Agricultural Statistics Service (2015) California grape acreage report 2015 crop. http://www.nass.usda.gov/Statistics_by_State/ California/Publications/Fruits_and_Nuts/20150grpac.pdf 
California Department of Food and Agriculture \& USDA National Agricultural Statistics Service (2016) California grape acreage report 2016 crop. http://www.nass.usda.gov/Statistics_by_State/ California/Publications/Fruits_and_Nuts/20150grpac.pdf

Campbell GS, Norman JM (1998) Heat flow in the soil. In: An introduction to environmental physics. Springer, New York

Cárcova J, Maddonni G, Ghersa C (1998) Crop water stress index of three maize hybrids grown in soils with different quality. Field Crops Res 55:165-174

Castellarin SD, Pfeiffer A, Sivilotti P, Degan M, Peterlunger E, Gaspero G (2007) Transcriptional regulation of anthocyanin biosynthesis in ripening fruits of grapevine under seasonal water deficit. Plant Cell Environ 30:1381-1399

Erdem Y, Arin L, Erdem T, Polat S, Deveci M, Okursoy H, Gültaş HT (2010) Crop water stress index for assessing irrigation scheduling of drip irrigated broccoli (Brassica oleracea L. var. italica). Agric Water Manag 98:148-156

Feldhake CM, Glenn DM, Edwards WM, Peterson DL (1997) Quantifying drought for humid temperate pastures using the Crop Water Stress Index (CWSI). New Zealand J Agric Res 40:17-23

Fuchs M (1990) Infrared measurement of canopy temperature and detection of plant water stress. Theor Appl Clima 42:253-261

Fuchs M, Tanner CB (1966) Infrared thermometry of vegetation. Agron J 58:597-601

Gates DM (1964) Leaf temperature and transpiration. Agron J $56: 273-277$

Hardie WJ, Considine JA (1976) Responses of grapes to waterdeficit stress in particular stages of development. Am J Enol Vitic 27:55-61

Horst TW, Weil JC (1992) Footprint estimation for scalar flux measurements in the atmospheric surface-layer. Bound-Layer Meteorol 59:279-296

Horst TW, Weil JC (1994) How far is far enough? The fetch requirements for micrometeorological measurement of surface fluxes. J Atmos Oceanic Technol 11:1018-1025

Hsieh CI, Katul G, Chi T (2000) An approximate analytical model for footprint estimation of scaler fluxes in thermally stratified atmospheric flows. Adv Water Resour 23:765-772

Idso SB (1982) Non-water-stressed baselines: a key to measuring and interpreting plant water stress. Agric Meteorol 27:59-70

Idso SB, Jackson RD, Pinter PJ, Reginato RJ, Hatfield JL (1981) Normalizing the stress-degree day parameter for environmental variability. Agric Meteorol 24:45-55

Irmak S, Haman DZ, Bastug R (2000) Determination of crop water stress index for irrigation timing and yield estimation of corn. Agron J 92:1221-1227

Jackson RD, Idso S, Reginato R, Pinter P Jr (1981) Canopy temperature as a crop water stress index indicator. Water Resour Res 17:1133-1138

Jackson RD, Kustas WP, Choudhury BJ (1988) A re-examination of the crop water stress index. Irrig Sci 9:309-317

Jones HG (1992) Plants and microclimate, 2nd edn. Cambridge University Press, Cambridge

Jones HG (2008) Irrigation scheduling- comparison of soil, plant and atmosphere monitoring approaches. Acta Hort 792:391-403

Kaimal JC, Finnigan JJ (1994) Atmospheric boundary layer flows. Oxford University Press, Oxford

Kennedy JA, Mathews MA, Waterhouse AL (2002) Effect of maturity and vine water status on grape skin and flavonoids. Am J Enol Vitic 53(4):268-274

Kustas WP, Nieto H, Morillas L, Anderson MC, Alfieri JG, Hipps LE, Villagarcía L, Domingo F, García M (2016) Revisiting the paper "Using radiometric surface temperature for surface energy flux estimation in Mediterranean drylands from a two-source perspective". Remote Sens Environ 184:645-653
Lee X, Massman WJ, Law BE (2004) Handbook of micrometeorology: a guide for surface flux measurement and analysis. Kluwer Academic, Dordrecht

Li L, Nielsen D, Yu Q, Ma L, Ahuja L (2010) Evaluating the crop water stress index and its correlation with latent heat and $\mathrm{CO}_{2}$ fluxes over winter wheat and maize in the North China plain. Agric Water Manag 97:1146-1155

Liu H, Peters G, Foken T (2001) New equations for sonic temperature variance and buoyancy heat flux with an omnidirectional sonic anemometer. Bound-Layer Meteorol 100:459-468

Maes W, Steppe K (2012) Estimating evapotranspiration and drought stress with ground-based thermal remote sensing in agriculture: a review. J Exp Bot 63:4671-4712

Massman WJ (2001) A simple method for estimating frequency response corrections for eddy covariance systems. Agric For Meteorol 104:185-198

Massman WJ, Lee X (2002) Eddy covariance flux corrections and uncertainties in long term studies of carbon and energy exchanges. Agric For Meteorol 113:121-144

Matthews MA, Anderson MM (1988) Fruit ripening in Vitis vinifera L: Responses to seasonal water deficits. Am J Enol Vitic 39:313-320

Matthews MA, Anderson MM, Schultz HR (1987) Fruit ripening in Vitis vinifera L: Responses to seasonal water deficits. Am J Enol Vitic 26:147-160

Matthews MA, Ishii R, Anderson MM, O’Mahony M (1990) Dependence of wine attributes on vine water status. J Sci Food Agric $51: 321-335$

Möller M, Alchanatis V, Cohen Y, Meron M, Tsipris J, Naor A, Ostrovsky V, Sprintsin M, Cohen S (2007) Use of thermal and visible imagery for estimating crop water status of irrigated grapevine. J Exp Bot 58(4):827-838

Nielsen D (1990) Scheduling irrigations for soybeans with the crop water stress index (CWSI). Field Crops Res 23:103-116

Nieto H, Kustas W, Gao F, Alfieri J, Torres A, Hipps L Impact of different within canopy wind attenuation formulations on modelling evapotranspiration using TSEB. Irrigation Science (in review)

Ochsner TE, Sauer TJ, Horton R (2007) Soil heat storage measurements in energy balance studies. Agron J 99:311-319

Ojeda H, Deloire A, Carbonneau A (2001) Influence of water deficits on grape berry growth. Vitis 40(3):141-145

Parry C, Nieto H, Guillevic P, Agam N, Kustas W, Alfieri J, McKee $\mathrm{L}$, McElrone $\mathrm{J}$ (this issue) An intercomparison of radiation partitioning models in vineyard canopies, Irrigation Science (in review) Reginato RJ, (1983) Field quantification of crop water stress. Trans of the ASAE 26:772-775

Schmid HP (2002) Footprint modelling for vegetation atmosphere exchange studies: a review and perspective. Agric For Meteorol 113:159-183

Semmens KA, Anderson MC, Kustas WP, Gao F, Alfieri JG, McKee L, Prueger JH, Hain CR, Cammalleri C, Tang Y, Xia T, Sanchez L, Alsina MM, Veléz M (2016) Monitoring daily evapotranspiration over two California vineyards using Landsat 8 in a multisensor data fusion approach. Remote Sens Environ 185:155-170

Steele D, Stegman E, Gregor B (1994) Field comparison of irrigation scheduling methods for corn. Trans of the ASAE 37:1197-1203

Tanner CB (1963) Plant temperatures. Agron J 55:210-211

Tanner CB, Thurtell G (1969) Anemoclinometer measurements of Reynolds stress and heat transport in the atmospheric surface layer. Research and Development Technical Report to US Army Electronic Command, ECOM 66-G22-F. Department of Soil Sciences, University of Wisconsin

Testi L, Goldhammer DA, Iniesta F, Salinas M (2008) Crop water stress index is a sensitive water stress indicator in pistachio trees. Irrig Sci DOI. https://doi.org/10.1007/s00271-008-0104-5 
Thom AS, Oliver HR (1977) On Penman's equation for estimating regional evaporation. Q J R Meteorol Soc 103:345-348

USDA Soil Conservation Service, Soil Survey of Sacramento County, California, 1993

Webb EK, Pearman GL, Leuning R (1980) Correction measurements for density effects due to heat and water vapour transfer. Q J Roy Meteorol Soc 106:85-100
Williams LE (2001) Irrigation of wine grapes. Pract Winery Vineyard J. http://www.practicalwinery.com/novdec01p42.html

Wilson KB, Goldstein A, Falge E, Aubinet M, Baldocchi D, Berbigier P, Bernhofer CH, Ceulemans R, Dolman H, Field C, Grelle A, Ibrom A, Law BE, Kowalski A, Meyers T, Moncrief J, Monson R, Oechel W, Tenhumen J, Valentini R, Verma S (2002) Energy balance closure at FLUXNET sites. Agric For Met 113:223-243 